\title{
ECONOMIA SOCIAL, NON-PROFIT SECTOR, TERCEIRO SETOR OU ECONOMIA SOLIDÁRIA: SENTIDOS, DIFERENÇAS E SIMILARIDADES
}

\author{
Susana Iglesias Webering ${ }^{1}$ \\ Universidade Federal Rural do Rio de Janeiro \\ suiwebering@gmail.com
}

\begin{abstract}
Resumo
Esse trabalho trata-se de um ensaio interpretativo e reflexivo a partir da revisão bibliográfica relacionada à Economia Social, ao Non-Profit Sector, Terceiro Setor e a Economia Solidária. Tem o objetivo de elucidar os conceitos e suas diferenças, uma vez que estão relacionados ao fenômeno da cooperação e autogestão, coletivos que desenvolvem dinâmicas organizacionais diferenciadas e que contrastam com a organização tradicional, baseada na hetero-gestão e voltada para o mercado. Verifica-se que existe um esforço por parte de poderes públicos, no âmbito científico e por parte dos seus protagonistas para classificar e fortalecer o campo, o que tem resultado em diferentes perspectivas. Em comum, esse campo concentra organizações que se diferenciam das empresas tradicionais e públicas, atendendo a uma parcela importante da população. Uma discussão histórica que evidencia como o fenômeno da cooperação não foi ainda adequadamente interpretado pelo pensamento organizacional, político e econômico.
\end{abstract}

Palavras-chave: Organizações. Economia social. Non-profit sector. Terceiro setor. Economia solidária.

\section{SOCIAL ECONOMY, NON-PROFIT SECTOR, THIRD SECTOR OR SOLIDARITY ECONOMY: MEANINGS, DIFFERENCES AND SIMILARITIES}

\begin{abstract}
This work is an interpretative and reflective essay based on the literature review related to Social Economy, NonProfit Sector, Third Sector and Solidary Economy. It has the objective of elucidating the concepts, their differences and unfolding, since they are related to the phenomenon of cooperation and self-management, collectives that develop different organizational dynamics and that contrast with the traditional organization, based on heteromanagement and oriented to the market. It is verified that there is an effort on the part of public powers, in the scientific scope and on the part of its protagonists to classify and to strengthen the field, which has resulted in different perspectives. In common, this field concentrates organizations that differ from traditional and public companies, serving a significant portion of the population. A historical discussion that shows how the phenomenon of cooperation has not yet been adequately interpreted by organizational, political and economic thinking.
\end{abstract}

Key words: Organizations. Non-profit sector. Social economy. Solidarity economy. Third sector.

\footnotetext{
${ }^{1}$ Professora adjunta na área de organizações do Departamento de Administração e Turismo (DAT) do Instituto Multidisciplinar (IM) da UFRRJ em Nova Iguaçu. Pós-doutorado no Programa de Pós- Graduação em Administração da UNIGRANRIO. Doutora em Engenharia de Produção pelo programa de Engenharia de Produção da COPPE/ UFRJ e Doutora em Economia Social pela Universidade de Valência (Espanha), com menção internacional (Doutorado Europeu). Mestre em Engenharia de Produção pelo programa de Engenharia de Produção da COPPE/ UFRJ e Bacharel em Administração pela Universidade Federal Rural do Rio de Janeiro (UFRRJ). Membro do Grupo de Pesquisa em Administração e Desenvolvimento (GPAD). Possui experiência em docência e pesquisa na área de Administração, com ênfase em estudos organizacionais, cooperação e autogestão.
}

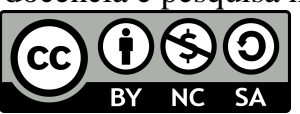




\section{INTRODUÇÃO}

Desde as últimas décadas do século XX vem aumentando o interesse por organizações mais democráticas, tanto modelos empresariais alternativos ao modelo tradicional de empresa capitalista (sendo a cooperativa o modelo clássico de organização autogestionária), quanto organizações de não mercado constituídas por outros tipos de organizações, como as associações e variedades de coletivos que vêm surgindo. Tem chamado atenção o desenvolvimento de um setor situado entre o setor privado e o setor público, bem como a importância e especificidade do papel desempenhado por essas organizações, despertando o interesse de políticos e cientistas sociais.

Tratam-se de necessidades sociais que desenvolvem uma forma de atuação e realização que não podem ser satisfeitas por agentes privados capitalistas nem pelas políticas públicas e macroeconômicas tradicionais (CHAVES; MONZÓN, 2008). Esse setor é por vezes denominado Economia Social, Non-Profit Sector, Terceiro Setor, Economia Social e Solidária ou, simplesmente, Economia Solidária. As definições contêm ainda fronteiras nebulosas (MONZÓN, 2006).

No Brasil, a expressão desse fenômeno foi o surgimento da Economia Solidária a partir da década de 1990, em meio à crise econômica e reestruturação produtiva, quando ganhou força um cooperativismo popular e solidário contrapondo o cooperativismo tradicional existente, antigo e de perspectiva mais liberal, estabelecendo-se um campo em disputa.

Nesse trabalho, trataremos de esclarecer esses conceitos e alguns elementos relacionados a tais definições, desenvolvendo um ensaio interpretativo e reflexivo baseado em revisão da literatura. Embora, em um primeiro momento possa parecer redundante, o aprofundamento desses conceitos evidencia a importância do estudo da especificidade dessas organizações e o setor a que pertenceriam, na medida em que repercute no campo, seja em termos de legislação, de políticas públicas e no sentido da construção de sua própria identidade. Uma discussão que evidencia como organizações baseadas na cooperação continuam emergindo mesmo em um ambiente hostil, de sociedades capitalistas e individualizadas, um fenômeno que ainda não foi adequadamente reconhecido pelo pensamento organizacional, político ou econômico (WEBERING, 2014).

Guerreiro Ramos desenvolveu a crítica das teorias organizacionais e da própria Administração enquanto ciência, alertando para o fato de que a organização de mercado é apenas um tipo de organização e a necessidade de se refundar a Administração sobre novas bases epistemológicas, para que se reconhecesse e abrangesse igualmente as múltiplas 
organizações existentes, "em sintonia com as realidades operativas de uma sociedade multicêntrica" (RAMOS, 1989, p. 156). Passados mais de trinta anos da publicação da Nova Ciência das Organizações, parece que ainda estamos longe de reconhecer "igualmente" a importância dos múltiplos modelos de organizações existentes.

\section{Economia Social}

O termo Economia Social é o mais antigo, surgiu na França no século XIX e se refere às organizações criadas por coletivos para atender suas necessidades de subsistência, bem como de resistência, diante das novas condições de vida geradas a partir do desenvolvimento do capitalismo industrial no século XVIII e XIX. Tratavam-se das associações, cooperativas e mutualidades criadas com base na ajuda mútua e no esforço associativo daquelas coletividades (MONZÓN, 2006). Portanto, as origens da Economia Social remetem às experiências do século XIX que deram origem a uma encruzilhada ideológica permeada de controvérsias entre socialistas, liberais, solidaristas e sociais cristãos (DEFOURNY, 1992).

Com as transformações ocorridas ao longo do século $\mathrm{XX}$ parece que houve uma dispersão no intuito de qualquer unidade. Primeiramente pela fragmentação das atividades cooperativas, mutualistas e associativas que se verificou no decorrer desse período: seja por sua estruturação em diferentes setores da economia; dificuldades relacionadas aos movimentos de trabalhadores; processo de institucionalização; fragmentação do movimento associativo em diversas direções. Segundo, o termo Economia Social passou a ser utilizado para designar diferentes campos de estudos socioeconômicos como, por exemplo, a economia da área da saúde, do seguro social, educação, sindicatos, etc. Passando essa expressão a ser utilizada como análoga aos fatores econômicos relacionados a diferentes esferas sociais (DEFOURNY, 1992).

Contudo, com a crise econômica do final da década de 1970 e início de 1980 diversos países da Europa enfrentaram o fechamento de empresas e várias cooperativas de trabalhadores emergiram, em alguns casos apoiadas por sindicatos mais progressistas (LECHAT, 2002). Nessa época observou-se, de modo especial na França, um esforço científico por delimitar e fortalecer o campo da Economia Social e de suas organizações constituintes que nunca deixaram de existir. Novamente, a Economia Social foi analisada de acordo com diferentes perspectivas (MONZÓN, 2006; DEMOUSTIER, 2001).

Nos demais países europeus a Economia Social se desenvolveu mais lentamente, embora tenham se destacado Espanha e Bélgica. Além disso, a Comissão das Comunidades 
Europeias havia criado a "Unidade de Economia Social" no âmbito de uma Direção Geral da União Europeia (DEFOURNY, 1992).

No início dos anos de 1990 o economista espanhol José Barea definiu para a Economia Social um setor empresarial e um setor de instituições privadas sem ânimo de lucro. O setor empresarial estaria subdividido em setor de sociedades não financeiras (como as cooperativas de produção, transformação, distribuição, comercialização e consumo) e setor de instituições de crédito (cooperativas de crédito, mútuas de crédito). Já o setor de instituições privadas sem ânimo de lucro incluiria associações, partidos políticos, sindicatos, fundações, clubes e federações esportivas, confrarias de pescadores, agricultores, etc (BAREA TEJEIRO, 1990).

O italiano Benedetto Gui desenvolveu uma análise também importante das microorganizações típicas desse setor, com base em categorias de agentes classificados em dominantes e beneficiários para estabelecer uma diferenciação entre organizações de benefício público e de benefício mútuo, que surgem como resposta a lacunas deixadas pelo mercado e setor público. As de benefício público se caracterizam pelo fato de sua categoria de beneficiários não controlar a organização, podem fazer uso desses serviços trabalhadores, pessoas que necessitam algum tipo de assistência, ou mesmo pequenas empresas. As de benefício mútuo se referem a organizações em que os membros são ao mesmo tempo a categoria dominante e beneficiária, como no caso de cooperativas. Outra característica é a menor, ou inexistente, apropriação de fluxos de renda próprios do setor privado capitalista (GUI, 1991). Essa concepção estava em consonância e contribuiu com a construção do marco teórico da Economia Social na década de 1990 na Europa (MONZÓN, 2006; BAREA TEJEIRO; JULIÁ; MONZÓN CAMPOS, 2000).

A pesquisa sobre a Economia Social ganhou força também quando foi criado no Centre International de Recherches et d'Information Sur 1'Economie Publique, Sociale et Coopérative (CIRIEC) um grupo de trabalho que contou com pesquisadores de dez países e gerou um estudo teórico e comparativo sobre a Economia Social no ano de 1992 intitulado Économie Sociale: entre économie capitaliste et économie publique. O intenso trabalho de pesquisa teve o objetivo de captar em cada país situações econômicas relacionadas a um "terceiro grande setor" (MONZÓN, 2006; DEFOURNY, 1992).

Além dos benefícios esperados por grupos de empresas e associações que fazem parte da Economia Social, o objetivo era o reconhecimento de uma dinâmica empresarial diferente da gestão capitalista e das iniciativas econômicas de poderes públicos. De acordo com Defourny, a atualidade da Economia Social se deve à tentativa mais que secular de criar uma 
esfera de atividades econômicas autônomas, cujo funcionamento se baseia em valores de solidariedade e democracia (DEFOURNY, 1992, p. 81).

Pode-se dizer ainda que na construção e disseminação do conceito tiveram papel importante também os protagonistas da Economia Social, por meio das diversas redes que desenvolveram. Uma delimitação foi estabelecida por ocasião da Conferência Europeia Permanente de Cooperativas, Mutualidades, Associações e Fundações, realizada em 2002: primazia da pessoa e do social sobre o capital; adesão voluntária e aberta; controle democrático pelos membros (exceto fundações que não têm sócios); conjunção entre os interesses dos sócios usuários e os interesses gerais; defesa e aplicação de princípios de solidariedade e responsabilidade; autonomia de gestão e independência em relação aos setores públicos; destino da maioria dos excedentes para a consecução de objetivos em favor do desenvolvimento sustentável, dos interesses de serviços dos membros e interesses gerais (MONZÓN, 2006).

Nessa declaração realizada pela representação de diversas organizações da Economia Social na Europa foi introduzido um elemento diferenciador referente ao princípio democrático, uma vez que se passou a incluir as fundações, que não possuem sócios, entre a família de organizações pertencentes à Economia Social, bem como entidades voluntárias sem fins lucrativos que podem não ser democráticas. Esses princípios foram então assumidos pelo Comitê Econômico e Social Europeu e o Parlamento Europeu (MONZÓN CAMPOS, 2010).

A Economia Social ressurgiu, primeiramente, com o objetivo de fortalecer sua representação perante o Estado, bem como adquirir melhores formas de financiamento. Segundo, os avanços teóricos e institucionais observados permitiram desenvolver uma relação entre o dinamismo associativo observado no séc. XIX e as organizações decorrentes deste, com as novas experiências econômicas e sociais que se desenvolveram a partir da década de 1970, entre elas: novas cooperativas, empresas recuperadas por trabalhadores, experiências de reinserção social pela via econômica, etc. Terceiro, com a crise do Estado do Bem Estar Social e do socialismo surgiram condições mais favoráveis para o reconhecimento de um setor que representasse as especificidades próprias dessas organizações (DEFOURNY, 1992).

De acordo com o informe elaborado por Chaves e Monzón (2008), promovido pelo Comitê Econômico e Social Europeu, cujo objetivo era apresentar um balanço da Economia Social nos estados membros da União Europeia, o que exigiu uma identificação comum das empresas e âmbito desse setor, os atores da Economia Social passaram a ser identificados em dois grandes subsetores, como segue.

Subsetor de mercado: integrado por organizações cuja fonte de recursos provém do mercado, já que produzem para a venda no mercado, são democráticas, os membros 
habitualmente acumulam a condição de sócio e usuário ou beneficiário da atividade, o que não impede que desenvolvam ações solidárias que transcendam sua base societária, com distribuição de benefícios não vinculada ao valor investido pelo sócio, mas de acordo com a atividade que eles realizam na organização, inclui as cooperativas, mutualidades, empresas similares, grupos empresariais da Economia Social, instituições sem fins lucrativos que estejam a serviço de outras entidades da Economia Social;

Subsetor de não mercado: organizações microeconômicas cujos recursos não provêm do mercado, mas de doações, quotas de sócios, financiamentos e rendas de propriedades, em sua maioria fundações e associações; não sendo de mercado fornecem produtos ou serviços de forma gratuita ou a preços não significativos (CHAVES; MONZÓN, 2008).

Em relação às cooperativas é importante lembrar que são as pioneiras na aplicação da responsabilidade social, através dos seus ideais de educação cooperativista, do princípio de portas-abertas (livre adesão), constituição de patrimônio conjunto dos sócios que é irrepartível entre eles, etc. O que não desvirtua sua base mutualística, já que atuam no mercado, desenvolvendo atividades de risco e das quais depende a prestação de serviços aos sócios. E ainda, o fato de poderem distribuir benefícios não quer dizer que o façam sempre. Existem os casos em que, por norma ou costume, não são distribuídos benefícios. Contudo, o critério de não distribuição de benefícios não é uma característica determinante para as empresas do subsetor de mercado da Economia Social (CHAVES; MONZÓN, 2008).

Em alguns casos o subsetor de mercado contempla outras formas jurídicas além de cooperativas (consideradas o principal agente empresarial da Economia Social) e mutualidades (na Europa, o segundo principal agente). São os casos das sociedades anônimas ou de responsabilidade limitada e, ainda, outras formas jurídicas de acordo com as legislações de cada país. Tratam-se de empresas criadas por trabalhadores que adotam processos democráticos e repartem benefícios de maneira igualitária, consideradas também empresas de Economia Social (CHAVES; MONZÓN, 2008).

As instituições sem fins lucrativos que estejam a serviço de outras entidades da Economia Social e consideradas pertencentes ao subsetor de mercado, são aquelas financiadas por quotas ou pagamentos de outras empresas ou grupos empresariais da ES por serviços prestados. Dependendo de para quem prestam serviços, são inscritas como sociedades não financeiras (se prestam serviços a cooperativas ou grupo de cooperativas) ou como instituições financeiras (se estão a serviço de cooperativas ou mutualidades de crédito).

A Economia Social dispõe de uma diversidade de recursos (financiamentos oriundos do mercado, do setor público ou de doações) e atores (sócios, assalariados, voluntariado, parceiros 
públicos e privados) que implicam diferentes dinâmicas e relacionamentos com o entorno. Como o caso do voluntariado, que está incorporado fundamentalmente no subsetor de não mercado, mas pode ocorrer também no subsetor de mercado. Os dois subsetores desenvolvem relações entre si e possuem uma característica em comum: envolvem entidades que desenvolvem atividades com o objetivo primeiro de satisfazer as necessidades das pessoas (CHAVES; MONZÓN, 2008, p.24).

No contexto europeu alguns países vêm conseguindo avanços no sentido do reconhecimento dessas organizações, via estratégia de consolidação de um setor econômico que envolve, inclusive, uma metodologia de contas satélites da Economia Social (BAREA TEJEIRO; MONZÓN CAMPOS, 2006). Além de amplamente divulgado na Europa, o conceito de Economia Social também é conhecido em alguns países da Ásia, África e América Latina. Sendo que a inclusão do subsetor de não mercado deixa confusos os limites conceituais com relação aos conceitos mais recentes de non-profit organizations (NPO) e Terceiro Setor (MONZÓN, 2006).

\section{Non-profit Sector e Terceiro Setor}

O conceito NPO é oriundo da literatura econômica anglo-saxônica das últimas décadas do séc. XX, onde proliferaram estudos sobre um Non-profit Sector e Terceiro Setor, gerando abordagens com base em critérios diferentes como (SALAMON; ANHEIER, 1992):

- definições legais existentes em cada país;

- definições econômico-financeiras que se baseiam no volume e fontes de recursos, determinam que se a organização tem mais da metade da fonte dos recursos no estado ou no setor privado, deve ser classificada respectivamente como pertencente ao setor público ou privado, permanecendo no Terceiro Setor somente aquelas cujas principais fontes de recursos sejam doações individuais ou familiares, o Sistema Nacional de Contas proposto pelas Nações Unidas, adota essa classificação;

definições funcionais com base na função executada pela organização, como servir aos interesses de populações desfavorecidas, advogar em prol da defesa de liberdade, direitos e mudanças sociais;

- definição estrutural operacional, que está relacionada aos critérios básicos de funcionamento.

Entre os tipos de classificação acima listados, após uma análise das vantagens e desvantagens de cada um, a definição estrutural e operacional foi indicada por Salamon e Anheier (1992) como o critério que possui mais vantagens, uma vez que é capaz de relacionar elementos comuns dessas organizações independentemente da localização geográfica e 
especificidades relacionadas às legislações. Essa classificação respeita a amplitude do setor, permite análises comparativas e hipóteses relacionadas às relações entre este e outros da vida econômica e social.

A classificação estrutural operacional foi mais disseminada a partir da colaboração de pesquisadores do Institute for Police Studies da Johns Hopkins University que desenvolveram uma pesquisa comparativa e internacional intitulada Johns Hopkins Comparative Non-Profit Sector Project. O estudo apontou que esse setor é definido por um conjunto de organizações que têm como características (SALAMON; ANHEIER, 1992):

- formalização: em alguns países são considerados algum tipo de formalização das atividades, contudo a formalização pode ser demonstrada, naqueles casos em que a legalidade não é o caminho adotado ou ainda é inviável, por uma organização permanente, seja através de encontros, atividades, procedimentos, etc;

- $\quad$ privada: NPO não fazem parte de governos, tampouco podem ser controladas por governos, o que não as impede de receber subvenções ou permitir que representantes oficiais tenham assento em seus conselhos;

- não distribui lucros: não retornar benefícios para os proprietários ou diretores, ainda que sejam acumulados no ano, estes devem ser reinvestidos para os fins próprios da organização;

- autogoverno: devem controlar suas próprias atividades, exercendo a governança sem o controle de entidades externas;

- $\quad$ voluntariado: devem desenvolver em algum nível o voluntariado, o que não quer dizer que a maioria de seu quadro seja de voluntários.

As Nações Unidas, em 2003, elaborou um manual para o sistema de contas nacionais com o objetivo de elaborar uma classificação internacional para as organizações sem fins lucrativos e viabilizar estatísticas padronizadas sobre o setor não lucrativo, estabelecendo como NPO no manual alínea 3.1: “organizations that are not-for-profit and, by law or custom, do not distribute any surplus they may generate to those who own or control them, and that are institutionally separate from government, self-governing and non-compulsory" (UNITED NATIONS, 2003, p.26).

O sistema de classificação foi elaborado com base no Johns Hopkins Comparative Non-Profit Sector Project que a partir do International Standard Industrial Classification of All Economic Activities e do estudo das realidades referentes às NPO em treze diferentes países (Estados Unidos, Reino Unido, França, Alemanha, Itália, Suécia, Japão, Hungria, Brasil, Gana, Egito, Índia e Tailândia) foi aperfeiçoado e testado a priori em onze 
países. Desde então, o sistema vem sendo aplicado por pesquisadores em uma ampla gama de países com diferentes níveis de desenvolvimento econômico e sistemas políticos, servindo de referência para o desenvolvimento de pesquisas e contas nacionais (UNITED NATIONS, 2003). No Brasil, o Instituto Brasileiro de Geografia e Estatística (IBGE) desenvolveu dados sobre as fundações privadas e associações sem fins lucrativos (nos anos 2006, 2008 e 2010) também com base nessa metodologia (AS FUNDAÇÕES PRIVADAS E ASSOCIAÇÕES SEM FINS LUCRATIVOS NO BRASIL, 2017).

Contudo, não é de se estranhar que uma classificação tão ampla e que se pretende universal gere contradições. Visto as diversas observações e limitações que o próprio manual estabelece, como a alínea 3.24: “cooperatives, mutual societies and self-help groups, provided that they meet the criteria spelled out in paragraph 3.1 above, would be classified according to their major economic activity [...]. To the extent that they distribute profits to members or directors, however, cooperatives and mutuals would be excluded from the non profit sector and therefore not classified" (UNITED NATIONS, 2003, p.33).

O termo non-profit é utilizado normalmente para diferenciar as organizações que produzem bens ou serviços, mas não distribuem benefícios, das organizações que produzem benefícios para seus próprios membros (entre elas cooperativas e mutualidades) e organizações privadas com finalidade de lucro propriamente. Portanto, o enfoque NPO acaba excluindo organizações que distribuem benefícios. O termo é contraditório, pois é requisito de qualquer organização ser superavitária, seja qual for a sua finalidade, ou seja, é preciso receitas maiores que as despesas. O uso impreciso do termo gera distorções na análise das organizações. Além disso, organizações classificadas como sem fins lucrativos podem desenvolver uma dinâmica estrutural/ operacional própria de organizações privadas com fins lucrativos (CABRAL, 2007).

Nesse sentido, também não é de se estranhar a ambiguidade referente à concepção de Terceiro Setor, que às vezes é utilizado indistintamente para se referir tanto às NPO como à Economia Social (MONZÓN, 2006) e, às vezes, ao adotar o elemento non-profit como requisito de organizações que desenvolvem missões sociais e conformam, como consequência, um espaço público não estatal, como é a tendência anglo-saxônica e que vem predominando no Brasil (CABRAL, 2007), também exclui de seu escopo cooperativas ou outros modelos de organização baseados na gestão democrática e propriedade coletiva. De fato, no Brasil a lei que regula as organizações da sociedade civil de interesse público (OSCIPs), lei 9790, exclui no seu artigo 2 as cooperativas (BIALOSKORSKI NETO, 2004).

A exclusão das cooperativas, seja das NPO, seja do Terceiro Setor, gera críticas, pois elas podem distribuir benefícios ou não, quando distribuem, o fazem de maneira pro-rata. Além 
disso, na perspectiva de Bialoskorski Neto (2004), cooperativas têm um caráter ainda mais peculiar, pois desenvolvem simultaneamente funções públicas e sociais: congregam geração e distribuição de renda; podem gerar ações relacionadas à saúde e formação. A concepção de Gui (1991) solucionou em parte a problemática da inserção ou não das cooperativas no Terceiro Setor com base na diferenciação entre organizações de benefício público e de benefício mútuo que surgem como resposta a lacunas deixadas pelo mercado e setor público. Para esse autor, também não existe uma diferença importante entre as funções econômicas de organizações de benefício mútuo (como as cooperativas) e as NPO (com mais frequência associadas ao conceito de Terceiro Setor), uma vez que a remuneração em cooperativas está vinculada à participação dos membros e não ao capital aportado. Contudo, se non-profit tem valor semântico de sem ser em benefício próprio, então NPO originalmente são as organizações de benefício público. Essas são as razões dos embates em torno à classificação (GUI, 1991).

Contudo, parece haver consenso no fato do Terceiro Setor ocupar um espaço intermediário entre o setor público e o privado de fins lucrativos e que com eles estabelece relações, cujas experiências nas últimas décadas passam por uma redescoberta em um momento sem precedentes do capitalismo mundial, de insuficiência de alternativas políticas e de crise do Estado Providência (CABRAL, 2007).

As variações das relações que permeiam organizações do Terceiro Setor ocorrem justamente em função da atuação do beneficiário (GUI, 1991). Por exemplo, no caso de cooperativas a categoria beneficiária e dominante é a mesma e exige comprometimento por parte dos beneficiários. Quanto mais se aproxima da caridade, maior é a separação entre a categoria dominante (doadores) e beneficiários. Exceções são encontradas entre organizações de ajuda ao desenvolvimento, em que gestores têm mais poder, assim como os beneficiários exercem maior participação, dependendo da metodologia empregada, porque funcionam como mediadoras de recursos doados por terceiros, alocando tais recursos em projetos locais. Essa configuração específica exige uma gestão diferenciada dos recursos. Já em organizações que atuam diretamente no mercado são mais comuns o benefício mútuo e a participação como categoria dominante e beneficiária. Isto porque transações realizadas por trabalhadores ou produtores envolvem relações diferenciadas, mais constantes e dependentes em relação ao mercado. Essas relações geram funções que estimulam um papel mais participativo, quando esse empoderamento não acontece pode expor um viés paternalista da organização. Esse viés pode se manifestar em cooperativas que não são fundadas pelos trabalhadores, como se observou no caso de experiências que ocorreram em períodos de crise, em que uma administração pública forma uma cooperativa de trabalhadores (desempregados) para trabalhar 
em obras públicas, o que em si pode ser visto também como uma forma de precarização das relações de trabalho. Nesse caso, a categoria beneficiária, ainda que conste no estatuto, não é a categoria dominante. Também o caso de lojas criadas com o objetivo de vender artesanatos ou produtos agrícolas de populações pobres, mas que em si não exercem poder em tal configuração de comercialização. Daí uma das principais críticas que sofre esse modelo de organização: a de que vem sendo utilizada como forma de precarização das relações de trabalho e perpetuação de relações de poder (CABRAL, 2007).

O Terceiro Setor é formado por organizações diferenciadas e normalmente é definido com base nas especificidades próprias dessas organizações, que podem ser de diversos níveis e tipos de formalização (algumas concepções inclusive reconhecem as que não estão formalizadas), fontes de financiamento, com estruturas híbridas, relações não necessariamente formais com o Estado, o mundo mercantil e as comunidades. Portanto, não é um setor estanque, o que dificulta qualquer classificação inflexível. Por essas razões, Cabral (2007) sugere ser mais adequado tratá-lo em termos de espaço social de atuação, que tem como decorrência relações que se manifestam em processos de gestão típicos desse setor. Como trata de representar interesses está dado o ingrediente político, o que torna a gestão ferramenta tão importante, podendo ser seu potencial ou fragilidade, constituindo em si um campo próprio de estudos (como é o caso da gestão social, gestão participativa e autogestão) e que deveria estar relacionado com questões qualitativas próprias da atividade pública e coletiva, sem pretender substituição ou equivalência em relação ao papel Estado.

Contudo, é compreensível a necessidade de classificação, seja como ferramenta de legitimação e representatividade, seja como mensuração para diversos fins, desde o desenvolvimento de políticas públicas a mecanismos de tributação e controle.

O Terceiro Setor sofre a crítica de que se desenvolveu como um setor de ajuste, como um paliativo em um contexto de liberalização das relações de mercado, desemprego estrutural e crise do bem-estar social, em que o Estado não supre as demandas sociais (CABRAL, 2007). Ao mesmo tempo, se reconhece que emergiu como um fenômeno orgânico, consequente das demandas e necessidades que compõem o campo dos movimentos sociais, não raros articulados com setores acadêmicos e entidades profissionais, que reivindicam a cidadania e o fortalecimento da sociedade civil na condução das políticas governamentais (PAULA, 2005).

No contexto europeu também se utiliza o termo Terceiro Setor de forma mais estendida, como um setor entre o privado com fins lucrativos e o público, sendo tratado como um setor específico do sistema econômico, normalmente dotado de subconjuntos de organizações, aquelas criadas por uns para benefício de outros e organizações de interesses mútuos que 
beneficiam os próprios membros, tendo se configurado como um ponto de encontro entre o Non-Profit Sector e a Economia Social, ainda que os conceitos não sejam totalmente coincidentes (CHAVES; MONZÓN, 2008).

\section{Economia Social e Solidária ou Economia Solidária}

Outra consequência daquele mesmo contexto da década de 1980 na Europa, com a retomada do termo Economia Social, foi o questionamento dos desdobramentos que as instituições tradicionais da Economia Social (cooperativas, mutualidades e associações) haviam alcançado ao longo do século XX, constatando a banalização dessas entidades, que se tornaram meramente um subconjunto do mercado e um subconjunto do papel de redistribuição do Estado. Era preciso reaproximar as atividades econômicas das relações de proximidade e solidariedade. Isto porque as organizações da Economia Social haviam se institucionalizado e a solidariedade se tornara abstrata: entre mutualistas anônimos, já que os sócios de grandes mutualidades não se conhecem; e na proposta de uma democracia representativa ao invés de uma democracia participativa em grandes organizações de Economia Social (DEMOUSTIER, 2001).

Essa crítica deu origem à proposta de uma Economia Social e Solidária ou somente Economia Solidária, que dá ênfase às atividades coletivas locais e de pequenas dimensões, em que possa haver uma efetiva autogestão dos empreendimentos, às vezes informais, que não estão associados a órgãos de representação ou federações, baseados em relações de solidariedade. A base para a expansão dessas experiências está no local, em oposição à globalização que dissemina as relações mercantis (DEMOUSTIER, 2001). O objetivo é não deixar que ocorra a fossilização entre a economia, o social e o político.

\section{O Contexto Brasileiro}

As práticas de cooperação surgiram no Brasil ainda colônia, inspiradas por ideais religiosos, práticas comunitárias e correntes do associacionismo operário que proliferavam na Europa e foram trazidas por imigrantes (PINHO, 2004). No fim do século XIX, fatores como a abolição da escravatura, a ausência de uma reforma agrária e a vinda de imigrantes europeus favoreceram o surgimento de um contingente de trabalhadores sobrantes a partir da formação do mercado de trabalho livre. A república, por meio da Constituição Federal do Brasil de 1891, assegurava a liberdade de associação dos trabalhadores, influenciando o desenvolvimento de experiências cooperativistas (PINHO, 2004; POCHMANN, 2012). 
O aumento significativo do cooperativismo contribuiu com que esse tipo de organização fosse reconhecida pela primeira vez em 1932 no decreto 22.239 (decretos anteriores haviam apenas começado a se referenciar em Rochdale e previam sua organização em sociedades anônimas), considerando cooperativas como sociedades de pessoas e não de capital, portanto de uma natureza jurídica diferenciada, garantindo uma razoável liberdade de funcionamento para as cooperativas (PONTES, 2004). Tanto que, de acordo com Pinho (2004), entre 1932 e 1964 o cooperativismo brasileiro se consolidou. No entanto, centrado na figura paternalista do Ministério da Agricultura, o que se estendeu aos Departamentos de Assistência ao Cooperativismo (DAC's) pertencentes às Secretarias de Agricultura dos Estados (PINHO, 2004, p.26-27).

A partir de 1966 o governo militar implementou um forte controle às cooperativas, revogando o decreto 22.239/32 e praticamente eliminando incentivos fiscais. Para Pinho (2004, p.36), o "ponto forte" desse período foi a "pacificação" do movimento cooperativista iniciado em 1968. O governo queria estimular a associação das cooperativas em sociedades civis estaduais, que viriam a incorporar as diversas "uniões" existentes, seriam as Organizações Cooperativas Estaduais (OCEs) encabeçadas pela Organização das Cooperativas Brasileiras (OCB). A OCB e as OCEs seriam sociedades civis, órgãos técnico-consultivos do Governo e para funcionar as cooperativas seriam obrigadas a se registrar.

Em pleno regime militar foi instituído o regime jurídico das sociedades cooperativas com a lei 5764 de 1971, ainda que vários de seus capítulos e artigos tenham sido derrogados com a Constituição Federal de 1988, vigora até os dias de hoje. Uma, entre tantas, de suas questões polêmicas é a designação da OCB como representação única do cooperativismo no Brasil (PINHO, 2004, p.39).

Pontes (2004) analisa em sua pesquisa a legislação cooperativista de 1971, destacando que ela está voltada principalmente para os ramos agropecuários, de consumo e crédito (que normalmente envolvem grande número de cooperados), não contemplando a realidade de uma variedade de atividades que também são desenvolvidas por cooperativas. E, ainda, a legislação cooperativista surgiu de maneira distorcida, utilizando-se do discurso de legalidade, neutralidade e igualdade, tratando da mesma forma a organização de latifundiários e trabalhadores despossuídos. Outro exemplo são generalizações como a exigência de um número mínimo de vinte pessoas para a constituição de uma cooperativa ou a obrigatoriedade de procedimentos como a convocação de assembleia ter de ser publicada em jornais de circulação local, informando data e local, bem como a pauta da reunião. Elementos como esses 
demonstram a inadequação de tal legislação, promulgada em um período caracterizado pelo autoritarismo centralizador e antidemocrático.

Entrando na década de 1990, o país foi marcado por um fenômeno de desemprego em massa e desassalariamento, quando ocorreu uma mudança substancial na estrutura ocupacional: de cada dez empregos criados, somente quatro eram assalariados, o que demonstrava a redução dos empregos com registro. Observou-se que uma parte considerável da população economicamente ativa (PEA) encontrou formas de se inserir no mercado de trabalho em ocupações de baixa remuneração e precárias: ocupações até mesmo sem remuneração, por conta própria, trabalho autônomo, em cooperativas, entre outros (POCHMANN, 2006).

Postos de trabalho assalariado foram transformados em trabalho autônomo, individual ou coletivo, por isso houve um "surto" de cooperativas de trabalho. Em qualquer dos casos o objetivo é o barateamento da força de trabalho (SINGER, 2002, p.1). As interpretações das cooperativas de trabalho como ferramenta de flexibilização são diversas, a defesa da sua continuidade foi bastante expressiva (inclusive por parte da OCB), ao mesmo tempo em que houve resistência e insistência em coibi-las, como no caso das ações desenvolvidas pelo Ministério Público do Trabalho (PONTES, 2004).

Até a década de 1990 considera-se o cooperativismo agropecuário o ramo do cooperativismo com maior atividade no país (OCB, 2013). Contudo, a partir dessa época, se observou um aumento no surgimento de cooperativas de trabalho, mas também educacionais, bem como o ressurgimento das cooperativas de habitação e crédito, pois suas operações ganharam mais flexibilidade (PINHO, 2004). Embora a OCB tenha incorporado os diversos ramos do cooperativismo nos seus conselhos, foi quase sempre presidida por produtores rurais que se relacionavam com o Estado via Ministério da Agricultura e com as Secretarias de Agricultura estaduais. De acordo com Pinho (2004), essa relação é histórica e remonta ao período em que a economia brasileira era baseada na agricultura.

Até o início da primeira década de 2000 a OCB continuava exercendo um papel forte de representação do cooperativismo, responsável por perpetuar a "doutrina cooperativista". No Brasil, houve a peculiaridade desse órgão de representação não ter surgido espontaneamente pela articulação das próprias cooperativas (SCHEDIWY, 1997), mas foi projetado pelo governo em um período autoritário, sofrendo um processo de fossilização, contribuindo com um movimento cooperativista passivo e apenas reativo às políticas do Estado (RIBEIRO, 2011). Todos esses elementos geram críticas contundentes à $\mathrm{OCB}$ e ao cooperativismo tradicional.

É importante observar que até então não havia um conceito que tratasse das especificidades próprias do tipo de organização cooperativa, muito menos do setor a que 
pertenceriam. Embora já existissem pesquisadores sobre o cooperativismo (PINHO, 2004), o conceito Economia Social não chegou ao Brasil, exceto como uma área da Teoria Econômica que estuda a eficiência da prestação de serviços públicos sociais (BIALOSKORSKI NETO, 2004).

Na década de 1990 e 2000 houve uma maior aproximação da discussão anglo-saxã de Terceiro Setor que, por sua vez, esteve relacionada a uma perspectiva privatizante e de redução do papel do estado. Expressão disto é o marco legal das organizações que se tornaram as principais referências no que se refere a Terceiro Setor no país: as Organizações da Sociedade Civil de Interesse Público (OSCIP), cuja finalidade é facilitar parcerias e convênios com todos os níveis de governos e órgãos públicos, permitem que doações realizadas por empresas possam ser descontadas no Imposto de Renda, é um tipo específico de organização regulada pela lei 9.790 de 1999 (BRASIL, 2017); as Organizações Sociais (OS), reguladas pela lei 9.637 de 1998 (BRASIL, 2017), uma qualificação outorgada pela Administração Pública para que possam receber fundos públicos para desenvolver atividades sem fins lucrativos, dirigidas ao ensino, à pesquisa, preservação do meio ambiente, cultura e saúde.

Nesse contexto conturbado começou a se desenvolver a discussão da Economia Solidária que, na ausência de uma tradição de estudos do que seria uma Economia Social, representa um avanço importante, apontando a diferenciação da organização que é econômica e social ao mesmo tempo, consolidando-se como um movimento para disputar o espaço da agricultura familiar (MOTTA, 2007) e dos pequenos empreendimentos autogestionários, reivindicando políticas públicas e legislação adequada. Um movimento que surgiu quando pesquisas começaram a evidenciar a importância dessas experiências. Na época, chamava atenção o fato dos atores que davam forma ao campo teórico da Economia Solidária estarem envolvidos no movimento através de cursos, assessorias e incubação de cooperativas. Uma articulação dos protagonistas dos empreendimentos, acadêmicos e, a partir de 2000, também uma rede de gestores públicos (WEBERING, 2005).

São considerados princípios da Economia Solidária: a autogestão, os trabalhadores deixam de estar subordinados a patrões, tomando decisões de forma participativa e coletiva; democracia, a força da Economia Solidária é a transformação estrutural das relações econômicas, o trabalho deixa de estar subordinado ao capital; a cooperação entre trabalhadores e empresas, como contraponto à competição; centralidade no ser humano e não no lucro; valorização da diversidade; emancipação e liberdade; valorização do saber local, da cultura e tecnologias sociais; valorização da aprendizagem e formação permanentes; justiça social na produção, comercialização, consumo, financiamento e desenvolvimento, contribuindo com a 
diminuição das desigualdades sociais e disseminação dos valores de solidariedade; cuidado com o meio ambiente e responsabilidade pelas gerações futuras (ECONOMIA SOLIDÁRIA, OUTRA ECONOMIA ACONTECE, 2007).

A Economia Solidária extrapola o cooperativismo formal (o qual tangencia, porém, não reconhecendo necessariamente todo cooperativismo como Economia Solidária), encontrando expressão também em empreendimentos informais coletivos, associações e até mesmo em pequenas empresas formalizadas através de outras formas jurídicas. Um fenômeno relacionado à economia informal e suas implicações (conjuntura econômica, histórica e cultural), bem como a inadequação da legislação cooperativista no Brasil.

A consolidação do movimento de Economia Solidária e a sua institucionalização via Secretaria Nacional de Economia Solidária (SENAES) criada em 2003 no âmbito do Governo Federal e que teve Paul Singer como secretário durante treze anos, além de secretarias em outros âmbitos da administração pública, eliminaria "de fato" a representação única da OCB (PINHO, 2004, p.9), pois muitos empreendimentos passaram a orientar-se pelo conceito de Economia Solidária.

Portanto, no Brasil se configurou um campo em disputa entre a vertente da Economia Solidária e o cooperativismo tradicional, duas vertentes do cooperativismo que têm gerado impasses, como a questão da atualização da legislação que ainda não foi resolvida. Além disso, a Economia Solidária não conseguiu uma maior visibilidade e ampliar seu diálogo. Ainda assim, é possível perceber que houve avanços em termos de políticas relacionadas ao cooperativismo, como as desenvolvidas pela SENAES e aquelas relacionadas à agricultura familiar que indiretamente tangenciam o trabalho associado, também a lei 12.690 de 2012 que trata especificamente da cooperativa de trabalho. Porém, tais políticas ainda são muito recentes e se considera que não representam políticas consistentes no sentido de consolidação de um setor diferenciado da economia, que contemple o cooperativismo bem como outras organizações de trabalho associado (WEBERING, 2014).

A Economia Solidária sofre a crítica de ser utópica e ver de forma ideologizada os empreendimentos econômicos solidários (EES), não abordando adequadamente questões relacionadas ao crescimento e ao fato de estarem inseridos no mercado, tanto que mais de dez anos depois do seu surgimento começa a reconhecer a complexidade desses desafios e a desenvolver um discurso no sentido de uma economia plural. Embora tenha representado um avanço, também não conseguiu dar conta das especificidades das NPO envolvidas com o campo, exemplo disso é o mapeamento realizado das entidades que prestam serviços e 
assessoria aos EES e que o conceito de Economia Solidária não contempla (WEBERING, 2014).

Tudo isso contribui com que no Brasil não exista o reconhecimento de um setor onde estejam agrupadas essas experiências. O embate vai além daquele entre o cooperativismo popular ou solidário e o cooperativismo tradicional - que não se vinculou nem mesmo àquela perspectiva ampliada de Terceiro Setor, mas ao setor privado de mercado -, engloba também aquelas que conformariam o subsetor de não mercado da Economia Social. Devido às especificidades do contexto brasileiro, existe inclusive a aversão ao uso do termo Terceiro Setor, mais conhecido e associado às organizações que se formam para desenvolver convênios com o Estado e angariar fundos, frequentemente envolvidas em escândalos de corrupção (WEBERING, 2014).

O impasse está longe de ser resolvido, mas a expectativa é que esse campo cresça no Brasil, mesmo com suas contradições. No âmbito acadêmico vem se notando maior interesse nas pesquisas (especialmente na área de estudos críticos organizacionais), projetos de extensão e até mesmo cursos que começam a surgir (WEBERING, 2010). No entanto, o problema da falta de uma unicidade pelo fortalecimento dessas experiências contribui com sua fragmentação, que se expressa no surgimento de movimentos e coletivos que nem mesmo conhecem a temática.

Considerações Finais

É possível observar que a discussão mais recente sobre os conceitos de Economia Social, Non-Profit Sector, Terceiro Setor, Economia Solidária, remete a diferentes perspectivas, assim como ocorreu sobre quais seriam as funções da Economia Social no século XIX na Europa. Isto porque a discussão da natureza econômica (ou não) dessas organizações está inserida no contexto mais amplo e complexo de organização das sociedades. A maneira como podem ser contextualizadas gera três perspectivas (DEMOUSTIER, 2001):

a visão liberal: observa a maior eficiência gerada pelas empresas de fins lucrativos, que fariam melhor uso dos recursos, cuja concorrência no mercado garante a sobrevivência das melhores empresas, gerando melhores resultados para os consumidores, as empresas coletivas surgem nesses contextos como formas paliativas para sanar os desequilíbrios próprios do mercado;

- a visão pluralista: considera que a economia deve ser plural, reconhecendo o espaço e a importância de outras formas de organização, explorando suas potencialidades;

a visão radical: reconhece na empresa coletiva uma prova concreta que o horizonte da empresa tradicional com fins lucrativos não é insuperável. 
Outro aspecto recorrente é como tais experiências e os debates que incitam ganham força nos momentos de crise. Portanto, tem importância compreender porque o fenômeno da cooperação continua emergindo mesmo em sociedades capitalistas, baseadas na racionalidade instrumental e comportamento individualista.

Enquanto alguns elementos são recorrentes a redescoberta desse campo nas últimas décadas apresenta algumas diferenças: a ampliação do objeto de estudo, o que contribuiu com a atual heterogeneidade desse setor, ao mesmo tempo em que se tornam menos claras as fronteiras em relação aos setores público e privado capitalista, bem como a economia doméstica e de autoconsumo, o que implicou também a incorporação de novas epistemologias para pensálo (como são as epistemologias sistêmicas, construtivistas, pós-modernas). Chegou-se a uma etapa tal de incongruências do sistema capitalista, que a "crise" vem se evidenciando cada vez mais latente e estrutural, não somente política e econômica, mas sobre os vínculos humanos e a natureza, o que vem apontando para novas, práticas, valores, formas organizativas e de consumo.

Em comum, esse campo - seja ele Economia Social, Economia Solidária, Terceiro Setor ou Non-Profit Sector - engloba organizações que se diferenciam das empresas tradicionais e públicas, preenchendo espaços que aquelas formas de organização não são capazes de suprir.

A cooperação nunca deixou de existir e formas coletivistas de organização continuam emergindo, existindo e viabilizando a sobrevivência de uma parcela importante da população, mesmo tendo sofrido uma obliteração, relegadas no pensamento econômico, político e organizacional. Até mesmo no âmbito do próprio movimento cooperativista que passou a se preocupar com a questão da profissionalização, em prol de uma racionalidade baseada em aspectos utilitários, de eficiência e produtividade.

Para reverter ou equilibrar esse cenário é necessário conhecer melhor os mecanismos da cooperação. As instituições desempenham papel fundamental, o chamado processo de isomorfismo (DIMAGGIO; POWELL, 2005), por isso através delas também seria possível contribuir com um ensino e pesquisas mais críticos, que reconheçam a pluralidade de organizações existentes e não continuem reproduzindo somente o modelo dominante de empresa e organização do trabalho. 


\section{REFERENCIAS}

BAREA TEJEIRO, J. Concepto y Agentes de la Economía Social. Revista de Economía Pública, Social y Cooperativa, Valencia, n. 8, p. 109-117, out. 1990.

BAREA TEJEIRO, J.; JULIÁ, J. F.; MONZÓN CAMPOS, J. L. Grupos Empresariales: la Economía Social ante los desafíos del mercado. In: Grupos Empresariales de la

Economía Social en España. Valencia: CIRIEC España, 2000 b. p.15-28.

BAREA TEJEIRO, J.; MONZÓN CAMPOS, J. L. Manual para la elaboración de las cuentas satélite de las empresas de La Economía Social: cooperativas y mútuas. Valencia: CIRIEC-España, 2006.

BIALOSKORSKI NETO, S. Cooperativismo é Economia Social, um ensaio para o caso brasileiro. III Seminário: Tendências do Cooperativismo Contemporâneo. Cuiabá - MT, 2004.

BRASIL. Lei no 9.637, de 15 de maio de 1998. Dispõe sobre a qualificação de entidades como organizações sociais. Disponível em http://www.planalto.gov.br/ccivil_03/leis/19637.htm , acesso em 31 de agosto de 2017. BRASIL. Lei no 9.790, de 23 de março de 1999. Dispõe sobre a qualificação de pessoas jurídicas de direito privado, sem fins lucrativos, como Organizações da Sociedade Civil de Interesse Público. Disponível em https://www.planalto.gov.br/ccivil_03/leis/19790.htm, acesso em 31 de agosto de 2017.

CABRAL, E. H. de. Terceiro Setor: gestão e controle social. São Paulo: Ed. Saraiva, 2007. CHAVES ÁVILA, R.; MONZÓN CAMPOS, J. L. La Economía Social en la Unión Europea. Comité Económico y Social Europeo. Bruxelles, 2008.

DEFOURNY, J. Orígenes, Contextos y Funciones de un Tercer Gran Sector. In: MONZÓN, J. L.; DEFOURNY, J. Economía Social: entre economía capitalista y economía pública. Valencia: CIRIEC España, 1992.

DEMOUSTIER, D. A Economia Social e Solidária. Porto Alegre: Loyola, 2001. DIMAGGIO, Paul J.; POWELL, Walter W. A Gaiola de Ferro Revisitada: Isomorfismo Institucional e Racionalidade Coletiva nos Campos Organizacionais. RAE, vo. 45, no. 2, abril-junho 2005, p.74-89.

ECONOMIA SOLIDÁRIA, OUTRA ECONOMIA ACONTECE: Cartilha da Campanha Nacional de Mobilização Social. Brasília: MTE, SENAES, FBES, 2007. 36p.

GUI, B. The Economic Rationale For The 'Third Sector: nonprofit and other noncapitalist organizations. Annals of Public and Cooperative Economics, Liège, vol. 61, n. 4, p. 553 $571,1991$. 


\section{AS FUNDAÇÕES PRIVADAS E ASSOCIAÇÕES SEM FINS LUCRATIVOS NO} BRASIL. IBGE, 2010. Disponível em

http://www.ibge.gov.br/home/estatistica/economia/fasfil/2010/default.shtm, acesso em 31 agosto de 2017.

LECHAT, N. M. P. Economia Social, Economia Solidária, Terceiro Setor: do que se trata? Civitas- Revista de Ciências Sociais, Porto Alegre, ano 2, n. 1, jun. 2002. MONZÓN CAMPOS, J. L. Economía Social y conceptos afines: fronteras borrosas y ambiguedades conceptuales del Tercer Setor. Revista de Economía Pública, Social y Cooperativa, Valencia, n.56, nov/ 2006, p. 9-24. MONZÓN CAMPOS, J. L. (Dir). Las Grandes Cifras de la Economía Social en España: ámbito, entidades y cifras clave. Año 2008. Valencia: CIRIEC, 2010. MOTTA, E. Economia solidária e agricultura familiar, uma integração necessária. Democracia Viva, v. 35, 2007, p. 80-84.

PAUlA, A. P. P. de. Por Uma Nova Gestão Pública. Rio de Janeiro: Editora FGV, 2005. OCB. Relatório OCB 2012: Cooperativas constroem um mundo melhor. Brasília: abril de 2013.

PINHO, D. B. O Cooperativismo no Brasil: da vertente pioneira à vertente solidária. São Paulo: Saraiva, 2004.

POCHMANN, M. Desempregados no Brasil. In: ANTUNES, R. (Org.) Riqueza e Miséria do Trabalho no Brasil. São Paulo: Boitempo, 2006. p.59-73.

POCHMANN, M. Nova Classe Média? O trabalho na base da pirâmide social brasileira. São Paulo: Boitempo, 2012.

PONTES, D. R. Configurações Contemporâneas do Cooperativismo Brasileiro: da economia ao direito. 199 f. Dissertação de mestrado. Setor de Ciências Jurídicas, Programa de Pós-Graduação em Direito. Universidade Federal do Paraná. Curitiba, 2004.

RAMOS, A. G. A Nova Ciência das Organizações. Rio de Janeiro: Editora da Fundação Getúlio Vargas, 1989.

RIBEIRO, J. C. V. C. La integracíon empresarial entre cooperativas agroalimentarias: um análisis de las políticas públicas en España y Brasil. 2011. 291p. Tese. Facultat d' Economia, Departament d' Economia aplicada. Universitat de Valéncia. Valencia, 2011. 
SALAMON, L. M.; ANHEIER, H. K. In search of the non-profit sector: the question of definitions. Voluntas: International Journal of Voluntary and Nonprofit Organizations November, Baltimore, vol. 3, issue 2, 1992, p. 125-151.

SCHEDIWY, R. La Teoría del Ciclo de Vida de los Holdings y Otros Grupos o Federaciones Cooperativos. Revista de Economía Pública, Social y Cooperativa, Valencia, n. 27, dez/ 1997, p. 7-21.

SINGER, P. Introdução à Economia Solidária. São Paulo: Editora Perseu Abramo, 2002. UNITED NATIONS. Handbook on Non Profit Institutions in the System of National Accounts. Department of Economic and Social Affairs. Studies in Methods (Série F), n. 91, 2003.

WEBERING, S. I. Conhecendo a realidade da Economia Solidária: o mapeamento de empreendimentos. 143 p. Dissertação (Mestrado) - Programa de Engenharia de Produção / COPPE, Universidade Federal do Rio de Janeiro, Rio de Janeiro, 2005.

WEBERING, S. I. Teoria Crítica e Teorias Organizacionais: uma relação possível?

GEPROS. Gestão de Produção, Operações e Sistemas. Ano 5, n.4, out-dez/ 2010. p. 139152.

WEBERING, S. I. Autogestão e Cooperação em uma Perspectiva Cooperativista e Sistêmica: o contexto cooperativo espanhol e brasileiro. 377f. Tese. Programa de Engenharia de Produção, COPPE. Universidade Federal do Rio de Janeiro. Rio de Janeiro, 2014. 